Document downloaded from:

http://hdl.handle.net/10251/75845

This paper must be cited as:

Benlloch Tinoco, M.; Varela Tomasco, PA.; Salvador Alcaraz, A.; Martínez Navarrete, N. (2012). Effects of Microwave Heating on Sensory Characteristics of Kiwifruit Puree. Food and Bioprocess Technology. 5(8):3021-3031. doi:10.1007/s11947-011-0652-1.

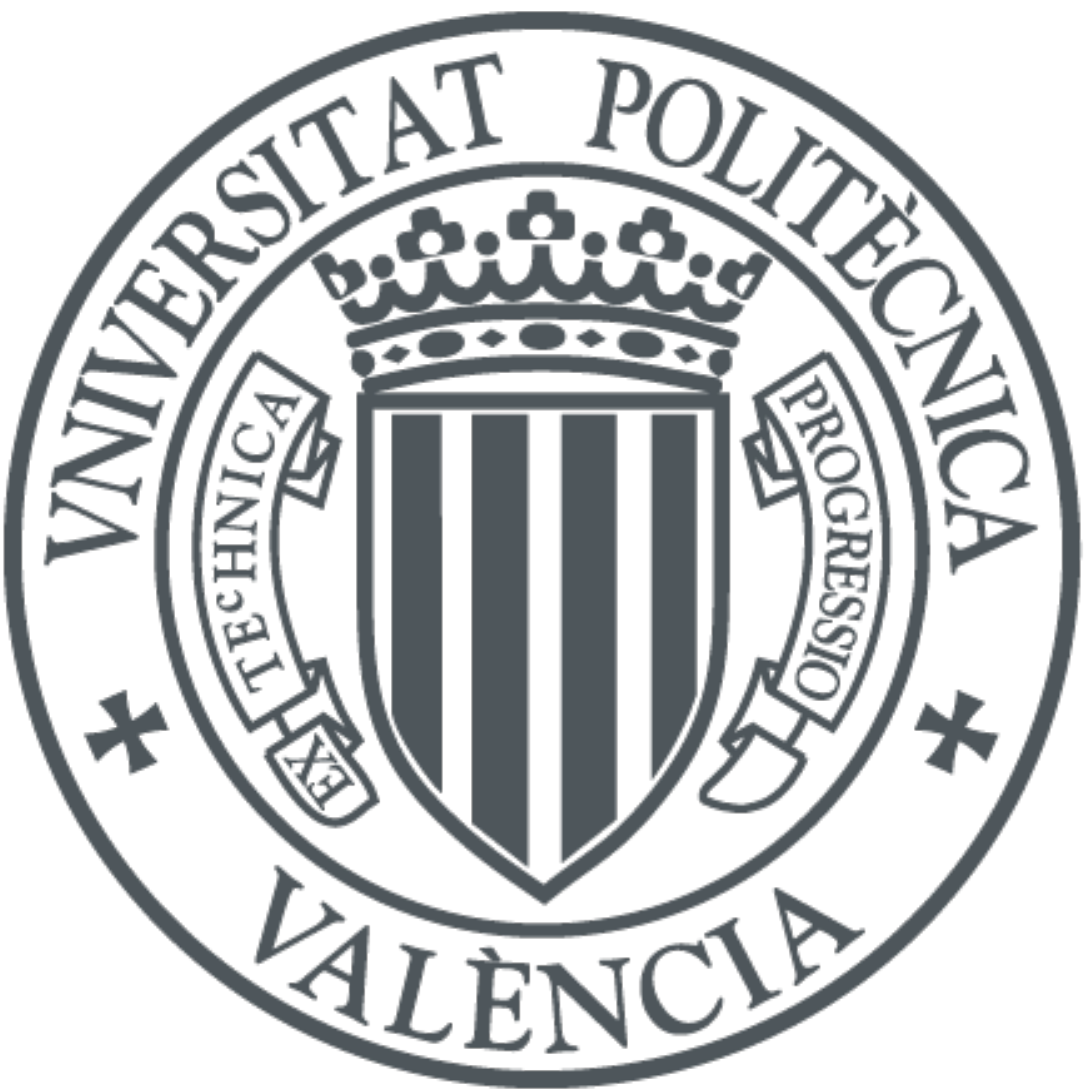

The final publication is available at

https://dx.doi.org/10.1007/s11947-011-0652-1

Copyright Springer Verlag (Germany)

Additional Information 


\section{EFFECTS OF MICROWAVE HEATING ON SENSORY CHARACTERISTICS OF KIWIFRUIT PUREE}

María Benlloch-Tinoco, ${ }^{1}$ Paula Varela, ${ }^{2}$ Ana Salvador, ${ }^{2 *}$ Nuria Martínez-Navarrete ${ }^{1}$

${ }^{1}$ Universidad Politécnica de Valencia, Food Technology Department, Food Investigation and Innovation Group, Camino de Vera s/n, 46022 Valencia, Spain ${ }^{2}$ Instituto de Agroquímica y Tecnología de Alimentos (CSIC), Avda. Agustín Escardino 7, 46980 Paterna, Valencia, Spain

*Corresponding author. Tel.: +34 9639000 22; fax: +34 9636363 01. Email address: asalvador@iata.csic.es (A. Salvador Alcaraz). 
Abstract: The effect of microwave processing on the characteristics of kiwifruit puree was evaluated by applying various gentle treatments. Different combinations of microwave power/processing time were applied, with power among 200-1000 W and time among 200-340 s, and various sensory and instrumental measurements were performed with the aim of establishing correlations and determining which instrumental parameters were the most appropriate to control the quality of kiwi puree. The water and soluble solids of the product, 83 and $14 \mathrm{~g} / 100 \mathrm{~g}$ sample, respectively, didn't change due to treatments. For sensory assessment, an expert panel was previously trained to describe the product. Fourteen descriptors were defined but only the descriptors 'typical kiwifruit colour', 'tone', 'lightness', 'visual consistency' and 'typical taste' were significant to distinguish between kiwifruit puree samples. The instrumental analysis of samples consisted in measuring consistency, viscosity, colour and physicochemical characteristics of the treated and fresh puree. Applying intense treatments $(600 \mathrm{~W}-340 \mathrm{~s}$, $900 \mathrm{~W}-300 \mathrm{~s}$ and $1000 \mathrm{~W}-200 \mathrm{~s}$ ) through high power or long treatment periods or a combination of these factors, mainly affects the consistency (flow distance decreased from 5.9 to $3.4 \mathrm{~mm} / \mathrm{g}$ sample), viscosity (increased from 1.6 to $2.5 \mathrm{~Pa} / \mathrm{s}$ ), colour (maximun $\Delta \mathrm{E}$ was 6 units) and taste of the product. As a result, samples were thicker and with an atypical flavour and kiwifruit colour due to increased clarity ( $\mathrm{L}^{*}$ increased from 38 to 43 ) and slight changes in the yellow-green hue ( $h^{*}$ decreased from 95 to 94 ). For the instrumental determinations of colour and visual perception of consistency, the most suitable parameters for quality control are the colour coordinates $L^{*}, a^{*}, h^{*}$, whiteness index and flow distance measured with a Bostwick consistometer.

Keywords: kiwifruit, microwaves, descriptive sensory assessment, colour, consistency, taste. 


\section{INTRODUCTION}

Sensory evaluation is an essential tool in the development of new products. Physical measurements cannot normally determine consumer response or preference because psychological or sensory responses are difficult to mimic (Dubost et al., 2003). However, this type of evaluation can be characterised by imprecision, inaccuracy and uncertain repeatability (Sinija \& Mishra, 2011). Therefore it is important to find a good objective method that can predict the sensory perception of the product (Segnini \& Dejmek, 1999).

Instrumental measurement of fruit properties such as ${ }^{\circ}$ Brix, acidity, texture or colour have become the cornerstones of fruit quality assessment (Oraguzie et al., 2009; Segnini \& Dejmek, 1999). The industry often sets quality standards that are based on instrumental measurements. Nevertheless, the relevance of these data will depend on how well they are able to predict sensory attributes (Oraguzie et al., 2009). In sensory analysis, one of the most important tools is the quantitative characterisation of the perceivable product attributes. In the bibliography, this tool is referred to as 'descriptive analysis' or 'profiling' and uses highly trained or expert panels with an acute ability to accurately characterise products (Worch et al., 2010).

Kiwifruit is native to China (Fisk et al., 2006; Fúster et al., 1994; Jaeger et al., 2003) and has become a popular fruit because of its good organoleptic and nutritional properties. This fruit has a relatively high content of nutraceuticals (Fisk et al., 2006), as well as a higher content of vitamin $\mathrm{C}$, zinc and potassium than other fruits such as oranges, apples or peaches (Beirão-da-Costa et al., 2006; Fang et al., 2008; Guldas, 2003). Kiwifruit also has important quantities of organic acids (citric, quinic, malic, galacturonic, succinic, oxalic, etc.), carotenoids, phenolic compounds, aromatic components (mainly esters, alcohols, aldehydes and ketones) and minerals (phosphorus, potassium, magnesium and calcium) (Soufleros et al., 2001; Zolfaghari et al., 2010). It is cultivated principally in New Zealand, but in recent years it has also become a commercial crop in several other countries: Australia, California, Japan, Chile and the Mediterranean countries, especially Italy and Spain (Fisk et al., 2006; Fúster et al., 1994). According to statistical data from MARM (the Spanish Ministry of the Environment, Rural Affairs and Coasts) 18,032 t of kiwifruit were produced in Spain in 2007, mainly in Pontevedra (8,032 t), Corunna (5,620 t) and Asturias (2,100 t). Spain has become the largest European kiwifruit importer. Consumption per capita is around 2 $\mathrm{kg} /$ person per year and Hayward is the most consumed variety (Jaeger et al., 2003; MAPA 2010). Generally, there is a surplus production of kiwifruit and it is a seasonal, sensitive and perishable fruit (Fang et al., 2008). Moreover, approximately 25\% of kiwifruit production may not reach fresh fruit marketing outlets because of inadequate quality in terms of small size or irregular shape (Park \& Luh, 1985) and so these fruits must be processed into various types of products (Fúster et al., 1994; Park \& Luh, 1985).

To compete successfully in world markets, horticultural industries must continue to offer innovative products (Jaeger et al., 2003). Kiwifruit has great potential for industrial exploitation due to its composition, sensory characteristics and stability during preservation (Barboni et al., 2010). Traditionally, kiwifruit has been processed to obtain fruit juice, jam or dehydrated products. The use of non-conventional technologies, such as microwave energy (MW), has some advantages when compared to conventional heating. Microwave energy, which is transported as an electromagnetic wave in certain frequency bands $(300 \mathrm{MHz}$ to $300 \mathrm{GHz})$, heats up dielectrical materials when impinges on them. Heating generated is due to the molecular friction of 
permanent dipoles within the material as they try to reorient themselves with the electrical field of the incident wave (Schubert \& Regier, 2010). It is important to take into account that MW energy is sufficient to move the atoms of a molecule, but is insufficient to cause chemical changes by direct interaction with molecules and chemical bonds. This occurs because MW are non-ionizing and theirs quantum energy is several orders of magnitude lower, compared to other types of electromagnetic radiation (Schubert \& Regier, 2010; Vadivambal \& Jayas, 2007).

The most important characteristic of microwaves is volumetric heating, which means that materials can absorb microwave energy directly and internally. This fact leads to higher penetrative power, faster heating rates, higher thermal efficiency and shorter processing times compared to conventional technologies (Vadivambal \& Jayas, 2007). All these facts seem to result in better organoleptic, nutritional and functional properties preservation, with a particular effect on colour and textural characteristics (Ancos de et al., 1999; Igual et al., 2010a; Igual et al., 2010b). Nevertheless, available information regarding the impact of microwaves on the sensory, nutritional and functional quality of products is scarce and inconsistent. Because of technical and cost factors, microwave heat treatment is not widely used for commercial purposes. The application of this technology, which seems to have a considerable potential for the processing of agricultural products in the near future, would be justified only from the standpoint of obtaining a high quality product (Vadivambal \& Jayas, 2007). For this reason, the study of the impact of microwave technology on food quality is interesting.

The aim of this work was to study the effect of applying a heat treatment based on the use of microwave energy with the objective of colour and texture preservation of kiwifruit puree. Instrumental and sensory evaluation of untreated product and product heated at different power-time conditions was performed with a prior selection of the attributes of interest. A correlation between the sensory measurements and the instrumentally obtained parameters was established in order to select the most suitable instrumental parameters to describe the quality of the product. To preserve most the characteristics of the fresh fruit, gentle microwave treatments were applied, taking into account that this technology could be combined with other technologies, for instance the use of biopreservatives, to obtain high quality and stable products. The most intense treatment was selected on the basis on a percentage of peroxidase (POD) and polyphenoloxidase (PPO) inactivation of 90 and $85 \%$, respectively, activity reduction comparable to pasteurization treatments (Igual et al., 2010b).

\section{MATERIALS AND METHODS}

\subsection{Sample preparation}

Kiwifruit (Actinida deliciosa var. Hayward) was purchased in a local supermarket. Fruit pieces $\left({ }^{\circ}\right.$ Brix between 13.4 and 14.7$)$ were peeled, washed with distilled water, cut into slices and finally triturated in a Thermomix (TM 21, Vorwerk, Spain), using the fourth power level for one minute. The crushing of the fruit was done in series of $1.5 \mathrm{~kg}$ batches. All of them were mixed and homogenised before receiving the corresponding treatments.

\subsection{Experimental design}

To study the simultaneous effect of the two processing variables (microwave power and process time) a central composite rotatable design was applied in order to select the 
treatment conditions with a reduced number of experimental trials (Cano et al., 1997; Beirão-da-Costa et al., 2006), using the Statgraphics 5.1 plus software program (StatPoint Technologies, Inc., Warrenton, VA, USA). The range entered in the program (300-900 W and 100-300 s) was selected taking into consideration previous experiences and ensuring that the most intense treatment would achieve a percentage of POD and PPO inactivation of 90 and $85 \%$, respectively. Treatment conditions defined by the experimental design appear in Table 1.

\subsection{Treatments}

A household microwave oven (3038GC, Norm, China) was used to obtain the processed puree. The nine different treatments (W-s) (Table 1) were carried out immediately after the kiwifruit was triturated. For each treatment, a sample of $500 \mathrm{~g}$ was heated in the microwave oven in a standard size glass beaker (BKL3-1K0-006O, Labbox, Spain). Treated samples (around $85-90^{\circ} \mathrm{C}$ ) were immediately cooled in ice-water to stop the heat treatment until the puree reached $30-35^{\circ} \mathrm{C}$. Cooked purees were then cold stored $(4$ ${ }^{\circ} \mathrm{C}$ ) for $24 \mathrm{~h}$ before analytical determinations.

\subsection{Analytical determinations}

All the treated samples and a non-treated sample used as control were instrumentally analysed as described below.

\subsubsection{Physicochemical properties}

Water and soluble solids content, water activity and $\mathrm{pH}$ were determined for fresh and processed kiwifruit puree. Water content $\left(\mathrm{x}_{\mathrm{w}}\right)$ was measured by drying the sample to constant weight at $60{ }^{\circ} \mathrm{C}$ in a vacuum oven, using AOAC 934.06 method (2000). Soluble solids were determined by measuring the ${ }^{\circ}$ Brix in a previously homogenised sample with a portable digital refractometer Refracto 3PX at $20{ }^{\circ} \mathrm{C}$ (Metler Toledo, Switzerland). Water activity $\left(\mathrm{a}_{\mathrm{w}}\right)$ was measured by using a dew point hygrometer (GBX FA-st lab, France) and $\mathrm{pH}$ in a digital $\mathrm{pH}$-meter Basic 2 (Crison, Spain). Each analysis was carried out in triplicate.

\subsubsection{Consistency and viscosity}

To determine the consistency, the flow distance $(\mathrm{mm} / \mathrm{g})$ of a controlled sample weight (about $40 \mathrm{~g}$ ) for a constant time (30 s) was measured with a Bostwick consistometer (Aname, Spain), employing the procedure described by Igual et al. (2010a).

Viscosity was measured using a rotational dial reading viscosimeter (LVT, Brookfield, Germany) with a R4 spindle. The viscosimeter measures the torque necessary to overcome the viscous resistance to the induced movement (Nielsen, 2010). The measurement was obtained inserting the spindle in a known kiwifruit puree weight (200 g) and reading the dial at different rotational speed levels $(6,12,30$ and $60 \mathrm{rpm})$. The dial reading was corrected taking into account the corresponding factor, which depends on the spindle and the rotational speed level used in each case, to obtain a viscosity expressed in cp (Ec. 1). All measurements were done in triplicate.

$\eta=L \cdot k$ 
where:

$\eta$ : viscosity (cp); $1 \mathrm{cp}=10^{-3} \mathrm{~Pa} \cdot \mathrm{s}$

L: dial reading;

k: factor (Chiralt et al., 1998).

\subsubsection{Colour measurement}

The colour of treated and fresh kiwifruit purees was measured in triplicate for each sample using a Minolta CM 3600D spectrocolorimeter (Konica Minolta Sensing, Inc., Japan). Samples were placed in size standardised sample cups $(37 \mathrm{~mm} \times 50 \mathrm{~mm} \times 22 \mathrm{~mm})$. The colour coordinates were obtained and results were expressed according to CIEL*a*b* uniform colour space $\left(10^{\circ}\right.$ observer and D65 illuminant), where: the $\mathrm{L}^{*}$ value is a measure of lightness (from 0 to 100 ); $a^{*}$ is a measure of chromaticity on a green $(-)$ to red $(+)$ axis and $b^{*}$ of chromaticity on a blue $(-)$ to yellow $(+)$ axis. Hue angle $\left(\mathrm{h}^{*}\right)$, chrome $\left(\mathrm{C}^{*}\right)$, total colour difference with respect to non-treated kiwifruit puree sample $\left(\Delta \mathrm{E}^{*}\right)$, browning index $(\mathrm{BI})$ (Maskan, 2001; Mohammadi et al., 2008) and whiteness index (WI) (Alegria et al., 2010; Moretti et al., 2007; Zanoni et al., 2007) were calculated from previously obtained colour coordinates by applying Eq. 2 to 6 . In Eq. 5, $x$ corresponds to the triestimulus coefficient, which can also be obtained from $\mathrm{L}^{*}$, $a^{*}$ and $b^{*}$ coordinates as described by Chiralt et al., (2007).

$$
h^{*}=a \tan \frac{b^{*}}{a^{*}}
$$

$$
C^{*}=\sqrt{a^{*^{2}}+b^{* 2}}
$$

$$
\Delta E^{*}=\sqrt{\Delta a^{* 2}+\Delta b^{* 2}+\Delta L^{* 2}}
$$

$$
B I=\frac{100(x-0.31)}{0.172}
$$

$$
W I=100-\sqrt{\left(100-L^{*}\right)^{2}+a^{*^{2}}+b^{*^{2}}}
$$

\subsection{Sensory assessment}

A sensory panel with eleven assessors (four men and seven women), recruited from students and employees of the Food Technology Department (Universidad Politécnica de Valencia) aged between 25-50 years old, was trained over a period of two months (twelve training sessions). Samples were cold-stored for $24 \mathrm{~h}$, tempered at $25^{\circ} \mathrm{C}$ before the assessment was carried out and served in plastic disposable standard size containers identified with three-digit codes. In all cases, training, and formal assessment, was performed in a normalised tasting room (UNE 8589 2010).

Selection of terms and panel training. The selection of descriptors was made over two 1 $\mathrm{h}$ sessions using the checklist method (Lawless \& Heymann 1998). Assessors were provided with two samples (the non-treated kiwifruit puree and the most intensively treated one) and descriptors were listed based on sensory analysis vocabulary (UNE 5492 2010). Panellists were asked to choose the most representative attributes to 
describe the samples. Once the terms were selected, consensus concerning their meaning was attained. This entailed reaching a precise definition of the descriptors and how to evaluate them to quantify attribute intensity, as well as agreeing upon the tasting procedure (Table 2) (Albert et al., 2009; Escribano et al., 2010; Pagliarini et al., 2010). During the training period, all the treated (Table 1) and the non-treated samples were tasted. Tests of three different samples in each session were used by the panellists for each descriptor, until the panel was homogeneous in the ranking of the samples. Panel members were then trained in the use of scales with reference samples $(10 \mathrm{~cm}$ unstructured scales for all the attributes). Panel performance was checked by ANOVA for discrimination ability and reproducibility of the panellists.

Formal assessment. A balanced complete block experimental design was carried out in duplicate (two different sessions) using the Compusense ${ }^{\circledR}$ program release five 4.6 software (Compusense Inc., Guelph, Ont., Canada) to evaluate the samples. The intensity of the sensory attributes were scored on a $10 \mathrm{~cm}$ unstructured line scale. Samples were randomly selected and served with a random three-digit code. All the treated samples (Table 1) were subjected to formal analysis, as well as the untreated sample.

\subsection{Statistical analyses}

Analysis of variance (ANOVA) with two factors (assessor and sample and their interaction) was run, with a confidence level of $95 \%(p<0.05)$, to check panel performance with the use of the Senpaq 4.2 package (QIstatistics, UK).

Analysis of variance (ANOVA) with one factor, with a confidence level of $95 \%$ $(\mathrm{p}<0.05)$, using the Statgraphics 5.1 plus software program (StatPoint Technologies, Inc., Warrenton, VA, USA) was applied to evaluate the differences among treatments on physicochemical and sensory data. In addition, principal component analysis (using a correlation matrix) and a Pearson correlation were made using the XLSTAT 2009 program, with the aim of studying the correlation between physicochemical parameters and sensory attributes.

\section{RESULTS AND DISCUSSION}

\subsection{Physicochemical properties}

No significant difference in measured physicochemical properties was found among samples (treated or non-treated). The average values (and standard deviation) obtained were $83.4(0.7) \mathrm{g}$ water/100 g product, $14.1(0.3) \mathrm{g}$ soluble solids/100 g liquid phase in the product, water activity $=0.983(0.002)$ and $\mathrm{pH}=3.39(0.07)$. These values are similar to those obtained by other authors for kiwifruit (Ancos de et al., 1999; Fúster et al., 1994; Zolfaghari et al., 2010).

\subsection{Consistency and viscosity}

The effect of microwave processing on kiwifruit puree consistency and viscosity is shown in Figure 1. According to Bourne (1982) consistency is defined as all the sensations resulting from stimulation of the mechanical and tactile receptors, especially in the region of the mouth and varying with the texture of the product. When the intensity of microwave treatment was higher, the flow distance of kiwifruit puree decreased, which means that consistency increased. Specifically, consistency of 300- 
$100,600-60$ and fresh samples was significantly lower than the rest of the samples $(p<0.05)$. However, the consistency of samples 600-200, 600-340, 900-300 and 1000200 was significantly higher. The rest of the samples had an intermediate behaviour. The consistency increase when a higher microwave power was applied can be related to the pectin solubilisation caused by the higher temperatures reached in the product. As it has been described, no significant change in total pectin content of fruits occurs due to heating treatments. Nevertheless, when microwave is applied, the water soluble pectin fraction increases while non-extractable and oxalate soluble fractions decrease, this affecting the mechanical response of the sample (Contreras et al., 2005 and 2007). An increase in the soluble pectin in the sample aqueous phase can be related with the increase in its consistency.

Viscosity is defined as the internal friction of a fluid or its tendency to resist flow (Bourne 1982). In the same way as occurs with consistency, product viscosity increased when a higher intensity microwave treatment was applied. In this case, samples 600340, 900-300 and 1000-200 showed significantly higher viscosity values than the rest of the samples with a confidence level of $95 \%$.

\subsection{Colour}

The colour of food is important for its acceptability and in consumer studies the first attribute that determines product quality is related to colour. Colour deterioration has been studied by several researchers for a number of products. In general, microwave heating seems to cause less browning in treated products than conventionally processed products (Vadivambal \& Jayas, 2007).

Table 3 shows the values of quantified colour parameters. Values obtained for colorimetric coordinates $\left(\mathrm{L}^{*}, \mathrm{a}^{*}\right.$ y $\left.\mathrm{b}^{*}\right)$, hue angle $\left(\mathrm{h}^{*}\right)$ and chrome $\left(\mathrm{C}^{*}\right)$ in fresh kiwifruit were similar to those published by Fisk et al. (2006). As regards lightness, a significant increase $(p<0.05)$ was observed in all cases when the most severe treatments were applied (Table 3). Samples 600-200, 600-340, 900-300 and 1000-200 were more luminous than the rest of the samples. The $a^{*}$ values increased as a consequence of different treatments- although this fact can only be taken as significant in samples 300 $300,600-340,900-300$ and 1000-200. Additionally, there were some changes in colorimetric coordinate $b^{*}$ values as a consequence of the processing, which generally increased when treatment intensity increased. In this manner, processed samples slightly changed to more red-yellow tones. The chrome $\left(C^{*}\right)$ value indicates the degree of colour saturation and is proportional to the strength of the colour. This parameter was nearly unchanged after microwave processing. Nevertheless, the hue angle $\left(h^{*}\right)$ values slightly decreased when microwave power increased during heating processes. This results in a displacement to a more red-yellow hue for microwave heated kiwifruit puree (Maskan, 2001). Total colour difference parameter combines L*, $a^{*}$ and $b^{*}$ parameters by integrating these three characteristics to compare the colour of non-treated samples with microwaved samples. In general, the $\Delta \mathrm{E}^{*}$ value increases when microwave power increases, as has been also observed by Ancos de et al., (1999). According to Bodart et al. (2008), $\Delta \mathrm{E}^{*}>3$ denotes differences noticeable to the human eye, thus noticeable colour difference was only found when the most aggressive treatments were applied. Heating treatments commonly cause enzymatic and non-enzymatic browning reactions. This fact leads a lightness reduction and, consequently, a browning index increment, as shown in results published by Maskan (2001). Nevertheless, according to Vadivambal \& Jayas (2007), the opposite phenomenon sometimes occurs. The values of BI obtained in this work were very similar for all the samples (Table 3). Despite significant 
differences among samples $(\mathrm{p}<0.05)$ being detected, the trend seems not to be attributable to the intensity of the treatment. The whiteness index (Table 3) followed a very similar behaviour to that observed for the $\mathrm{L}^{*}$ coordinate, with significantly higher values for the more intensely treated products. From this point of view, colour changes observed during treatments may be more related to degradative loss of total pigments (chlorophyll and xanthophyll) during heating (Ancos de et al., 1999; Maskan, 2001), than to browning reactions.

\subsection{Sensory assessment}

Significant differences $(p<0.05)$ among samples were only found in the sensory descriptors 'typical kiwifruit colour', 'tone', visual consistency', 'lightness' and 'atypical taste'.

As a general rule, noticeable differences increased for five considered descriptors (see Figure 2) in treated samples compared with untreated samples when heating intensity increased. Figure 2A shows that differences were not found between fresh kiwifruit puree and processed samples (200-200, 300-100 and 600-60) as the lines in the spiderplot were nearly overlapping. It has to be mentioned that the visual consistency of treated samples was slightly lower than fresh samples, although no significant differences $(p>0.05)$ were found among the four samples considered. Figure $2 B$ shows higher differences in every significant attribute between treated samples and fresh kiwifruit puree, except in 'visual consistency'. Panellists considered samples 600-200 and 900-100 less light and with lower 'typical kiwifruit colour intensity' than fresh puree. Nevertheless, observed differences between sample 300-300 and the fresh sample were not statistically significant $(p>0.05)$ with regard to these descriptors. Moreover, these three samples seemed to be significantly $(\mathrm{p}<0.05)$ browner than fresh kiwifruit puree. Although treated samples were not truly browner than the untreated sample, this fact can be related to how the attribute 'tone' was defined (Table 2). Panellists probably considered that the treated samples had a less green tone, for this reason they situated the samples on the opposite side of the scale (green/brown) and this action resulted in considering the treated sample as browner than the fresh sample. Figure $2 \mathrm{C}$ evidences bigger differences in assessments given to samples 600-340, 900-300 and 1000-200 compared to fresh kiwifruit puree. In a general way, panellists considered that the three processed samples were significantly $(p<0.05)$ less lightness and green, with a lower typical kiwifruit colour intensity and higher atypical taste intensity; however they had the same visual consistency as fresh kiwifruit puree.

Figure 3 shows the two first component map of the principal component analysis constructed using the sensory data. Two components were extracted that explain $80.59 \%$ of the data variability. The first component explained most of this variance $(63.83 \%)$, for this reason it has been used to describe all the kiwifruit puree characteristics. This component evidenced a positive correlation with the sensory attributes 'typical kiwifruit colour intensity', 'kiwifruit odour intensity', 'lightness', 'acidity', 'astringency', 'intensity kiwifruit taste' and a negative correlation with the sensory attributes 'atypical odour', 'tone', 'atypical taste', 'visual consistency' and 'mouth consistency'. Samples 200-200, 300-100, 600-60 were characterised by a similar acidity, astringency, colour, odour and taste to the fresh kiwifruit, due to the less intensive treatments being applied to these samples. On the other hand, when the most severe treatments were applied (600-340, 900-300 and 1000-200), the samples were characterised by a higher atypical odour and taste, higher visual and mouth consistency 
and more browning. Finally, the granularity and consistency of samples 300-300, 600200 and 900-100 were higher than the rest of the samples.

\subsection{Correlation between instrumental and sensory data}

A Pearson correlation matrix was constructed using the instrumental and sensory data. Correlation coefficient values obtained are summarised in Table 4. Significant $(p<0.05)$ and meaningful correlations were found between some instrumental colour parameters $\left(\mathrm{L}^{*}, \mathrm{a}^{*}, \mathrm{~h}^{*}\right.$ and $\left.\mathrm{WI}\right)$ and sensory descriptors 'typical kiwifruit colour', 'tone' and 'lightness'. 'Typical kiwifruit colour' and 'lightness' were negatively correlated with $\mathrm{L}^{*}, \mathrm{a}^{*}$ and WI and positively correlated with $\mathrm{h}^{*}$. The opposite situation was observed for descriptor 'tone' which was negatively correlated with $\mathrm{h}^{*}$ and positively correlated with $\mathrm{L}^{*}, \mathrm{a}^{*}$ and WI. In addition, a negative correlation was found between flow distance and 'visual consistency' determined by sensory assessment, which means that instrumental and sensory consistency were positively correlated.

\section{CONCLUSIONS}

Applying intense treatments of high microwave power mainly affected the colour and taste of kiwifruit puree. This fact is shown through different instrumental and sensory parameters obtained for the treated and fresh purees. The most appropriate parameters for quality control of this product, among those considered in this study, were the colour parameters $\mathrm{L}^{*}, \mathrm{a}^{*}, \mathrm{~h}^{*}$, WI as well as flow distance measured with a Bostwick consistometer. These parameters were the only ones that showed significant and meaningful correlations with sensory descriptors. As regards to instrumental analysis, the most intensive processed samples (600-340, 900-300 and 1000-200) were significantly thicker, more viscose and had a greater lightness increment than the rest of the samples. Concerning sensory assessment, perceivable significant differences were only found between kiwifruit puree samples in some descriptors ('typical kiwifruit colour', 'tone', 'lightness', 'visual consistency' and 'typical taste'), which increased when microwave power increased. The most severely treated samples showed the highest variation in these parameters. In this sense, microwave could be considered an interesting technique to treat the samples although much care has to be taken with the intense treatments.

Acknowledgements: The authors thank the Ministerio de Educación y Ciencia for the financial support given throughout the Project AGL 2010-22176. The authors are indebted to the Generalitat Valenciana, (Valencia, Spain) for the Grant awarded to the author Maria Benlloch. The translation of this paper was funded by the Universidad Politécnica de Valencia, Spain.

\section{REFERENCES}

Albert A, Varela P, Salvador A \& Fiszman S M (2009) Improvement of crunchiness of battered fish nuggets. European Food Research and Technology, 228, 923-930.

Alegria P, Pinheiro J, Gonçalves EM, Fernandes I, Moldao M \& Abreu M (2010) Evaluation of a pre-cut heat treatment as an alternative to chlorine in minimally processed shredded carrot. Innovative Food Science and Emerging Technologies, 11, $155-161$. 
Ancos de B, Cano MP, Hernández A \& Monreal M (1999) Effects of microwave heating on pigment composition and color of fruit purees. Journal of the Science of Food and Agriculture, 79, 663-670.

AOAC (2000) Official Methods of Analysis of AOAC International. MD, Gaithersburg, USA.

Barboni T, Cannac M \& Chiaramonti N (2010) Effect of cold storage and ozone treatment on physicochemical parameters, soluble sugars and organic acids in Actinidia deliciosa. Food Chemistry, 121, 946-951

Beirão-da-Costa S, Steiner A, Correia L, Empis J \& Moldão-Martins M (2006) Effects of maturity stage and mild heat treatments on quality of minimally processed kiwifruitfruit. Journal of Food Engineering, 76, 616-625.

Bodart M, de Peñaranda R, Deneyer A \& Flamant G (2008) Photometry and colorimetry characterisation of materials in daylighting evaluation tools. Building and Environment, 43, 2046-2058.

Bourne MC (1982) Food Texture and Viscosity-Concept and Measurement. Academic Press, New York, USA.

Cano MP, Hernández A \& Ancos de B (1997) High Pressure and Temperature Effects on Enzyme Inactivation in Strawberry and Orange Products. Journal of Food Science, 62(1), 85-88

Chiralt A, Martínez-Navarrete N, Camacho MM \& González C (1998) Experimentos de fisicoquímica de alimentos. Editorial Universidad Politécnica de Valencia, Valencia, Spain (Chapter 3).

Chiralt A, Martínez-Navarrete N, González C, Talens P \& Moraga G (2007) Propiedades físicas de los alimentos. Editorial Universidad Politécnica de Valencia, Valencia, Spain, (Chapter 16).

Contreras C, Martín ME, Martínez-Navarrete N, Chiralt A (2005) Effect of vacuum impregnation and microwave application on structural changes occurred during air drying of apple. Food Science and Technology/LWT, 38(5), 471-477.

Contreras C, Martín-Esparza ME, Martínez-Navarrete N, Chiralt A (2007) Influence of osmotic pre-treatment and microwave application on properties of air dried strawberry related to structural changes. European Food Research and Technology, 224, 499-504.

Dubost NJ, Shewfelt RL \& Eitenmiller RR (2003) Consumer acceptability, sensory and instrumental analysis of peanut soy spreads. Journal of Food Quality, 26, 27-42.

Escribano S, Sánchez F J \& Lázaro A (2010) Establishment of a sensory characterization protocol for melon (Cucumis melo L.) and its correlation with physical-chemical attributes: indications for future genetics improvements. European Food Research and Technology, 231, 611-621.

Fang L, Jiang B \& Zhang T (2008) Effect of combined high pressure and thermal treatment in kiwifruit peroxidase. Food Chemistry, 109, 802-807.

Fisk CL, McDaniel MR, Strick BC \& Zhao Y (2006) Physicochemical, Sensory, and Nutritive Qualities of Hardy Kiwifruit (Actinidia arguta 'Ananasnaya') as Affected by Harvest Maturity and Storage. Sensory and Nutritive Qualities of Food, 71(3), 204-210.

Fúster C, Préstamo G \& Cano MP (1994) Drip Loss, Peroxidase and Sensory Changes in Kiwi fruit Slices During Frozen Storage. Journal of the Science of Food and Agriculture, 64, 23-29.

Guldas M (2003) Peeling and the physical and chemical properties of kiwi fruit. Journal of Food Processing Preservation, 27, 271-284. 
Igual M, Contreras C \& Martínez-Navarrete N (2010a). Non-conventional techniques to obtain grapefruit jam. Innovative Food Science and Emerging Technologies, 11, 335341.

Igual M, García-Martínez E, Camacho MM and Martínez-Navarrete N (2010b). Effect of thermal treatment and storage on the stability of organic acids and the functional value of grapefruit juice. Food Chemistry, 118, 291-299.

Jaeger SR, Rossiter KL, Wismer WV \& Harker FR (2003) Consumer-driven product development in the kiwifruit industry. Food Quality and Preference, 14, 187-198.

Lawless H \& Heymann H (1998) Sensory evaluation of food, Principles and practices. Chapman \& Hall, New York, USA.

MAPA (2010) Plataforma de conocimiento para el medio rural y pesquero. National Agricultural Statistics Database, Spain, Available at: www.mapa.es. Accessed 05 October 2010.

Maskan M (2001) Kinetics of colour change of kiwifruits during hot air and microwave drying. Journal of Food Engineering, 48, 169-175.

Mohammadi A, Rafiee S, Emam-Djomeh Z \& Keyhani A (2008) Kinetic Models for Colour Change in Kiwifruit Slices During Hoy Air Drying. World Journal of Agricultural Sciences, 4 (3), 376-383.

Moretti CL, Mattos LM, Machado CMM \& Kluge RA (2007) Physiological and quality attributes associated with different centrifugation times of baby carrots. Horticultura Brasileira, 25, 557-561.

Nielsen SS (2010) Food analysis laboratory manual. Springer, USA.

Oraguzie N, Alspach P, Volz R, Whitworz C, Ranatunga C, Weskett R \& Harker R (2009) Postharvest assessment of fruit quality parameters in apple using both instrument and an expert panel. Posthaverst Biology and Technology. 52, 279-287.

Pagliarini E, Laureati M \& Lavelli V (2010) Sensory evaluation of gluten-free breads assessed by a trained panel of celiac assessors. European Food Research and Technology, 231, 37-46.

Park EY \& Luh BS (1985) Polyphenol Oxidase of Kiwifruit. Journal of Food Science, 50, 678-684.

Schubert H \& Regier M (2010). The microwave processing of foods. Woodhead Publishin Limited, UK.

Segnini S, Dejmek P \& Öste R (1999) Relationship between instrumental and sensory analysis of texture and colour of potato chips. Journal of Texture Studies, 30, 677690.

Sinija VR \& Mishra HN (2011). Fuzzy Analysis of Sensory Data for Quality Evaluation and Ranking of Instant Green Tea Powder and Granules. Food Bioprocess Technology, 4, 408-416.

Soufleros EH, Pissa I, Petridis D, Lygerakis M, Mermelas K, Boukouvalas G \& Tsimitakis E (2001) Instrumental analysis of volatile and other compounds of Greek kiwi wine; sensory evaluation and optimization of its composition. Analytical, Nutritional and Clinical Methods Section, 75, 487-500.

Vadivambal R \& Jayas DS (2007) Changes in quality of microwave-treated agricultural products-a review. Biosystems Engineering, 98, 1-16.

Worch T, Lê S \& Punter P (2010) How reliable are the consumers? Comparison of sensory profiles from consumers and experts. Food Quality and Preference, 21, 309318.

Zanoni B, Lavelli V, Ambrosoli R, Garavaglia L, Minati J \& Pagliarini E (2007) A model to predict shelf-life in air and darkness of cut, ready-to-use, fresh carrots under 
537 both isothermal and non-isothermal conditions. Journal of Food Engineering, 79, 538 586-591.

539 Zolfaghari M, Sahari MA, Barzegar M \& Samadloiy H (2010) Physicochemical and 540 Enzymatic Properties of Five Kiwifruit Cultivars during Cold Storage. Food 541 Bioprocess Technology, 3, 239-246. 


\section{Tables Index}

Table 1. Microwave power levels and time used in the different treatments.

Table 2. Attributes, scale extremes and evaluation technique used in descriptive sensory assessment of kiwifruit puree treated with microwave.

Table 3. Average values (and standard deviation) of colour coordinates ( $\mathrm{L}^{*}, \mathrm{a}^{*}$ and $\mathrm{b}^{*}$ ), chrome $\left(\mathrm{C}^{*}\right)$, hue angle $\left(\mathrm{h}^{*}\right)$, total colour difference $\left(\Delta \mathrm{E}^{*}\right)$, browning index $(\mathrm{BI})$ and whiteness index (WI) of fresh and treated samples. The same letter in superscript (a, b, c or $d)$ indicates homogeneous groups established by the ANOVA $(p<0.05)$.

Table 4. Correlation coefficient values between different sensory and instrumental parameters. Values in bold are statistically significant $(\mathrm{p}<0.05)$.

\section{Figure Captions}

Figure 1. Average values (and standard deviation) of viscosity and flow distance $(\mathrm{mm} / \mathrm{g})$ of fresh and treated samples. The same letter ( $\mathrm{a}, \mathrm{b}$ or $\mathrm{c}$ ) indicates homogeneous groups established by the ANOVA $(\mathrm{p}<0.05)$.

Figure 2A. Average values (on a 1-10 scale) of panel member assessments about kiwifruit colour, tone, lightness, visual consistency and atypical taste of treated samples 200-200, 300-100, 300-300 and 600-60 compared to fresh sample.

Figure 2B. Average values (on a 1-10 scale) of panel member assessments about kiwifruit colour, tone, lightness, visual consistency and atypical taste of treated samples 300-300, 600-200 and 900-100 compared to fresh sample.

Figure 2C. Average values (on a 1-10 scale) of panel member assessments about kiwifruit colour, tone, lightness, visual consistency and atypical taste of treated samples 600-340, 900-300 and 1000-200 compared to fresh sample.

Figure 3. Two first components of principal component analysis (PCA) plot of fresh and treated samples and sensory attributes. 


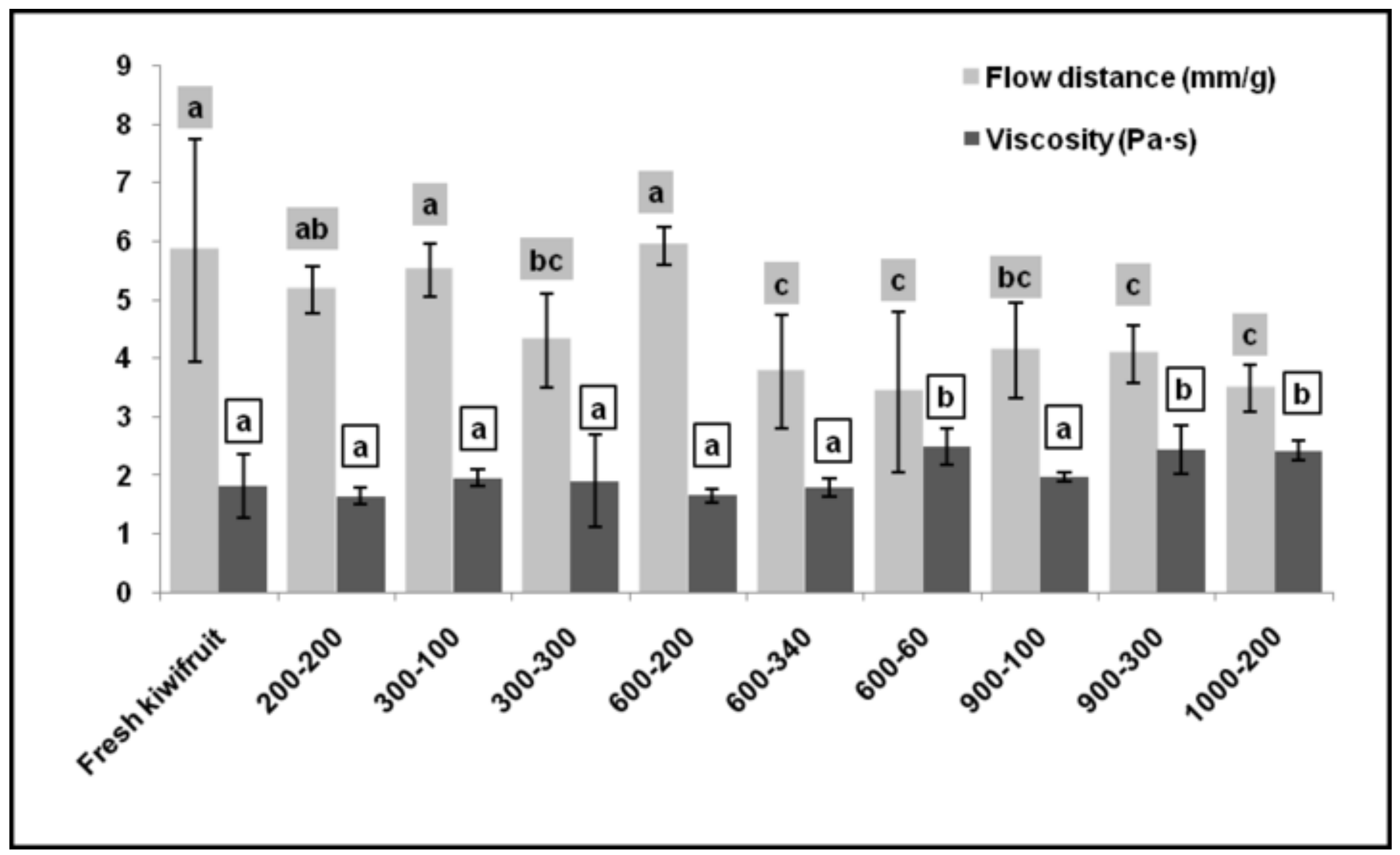




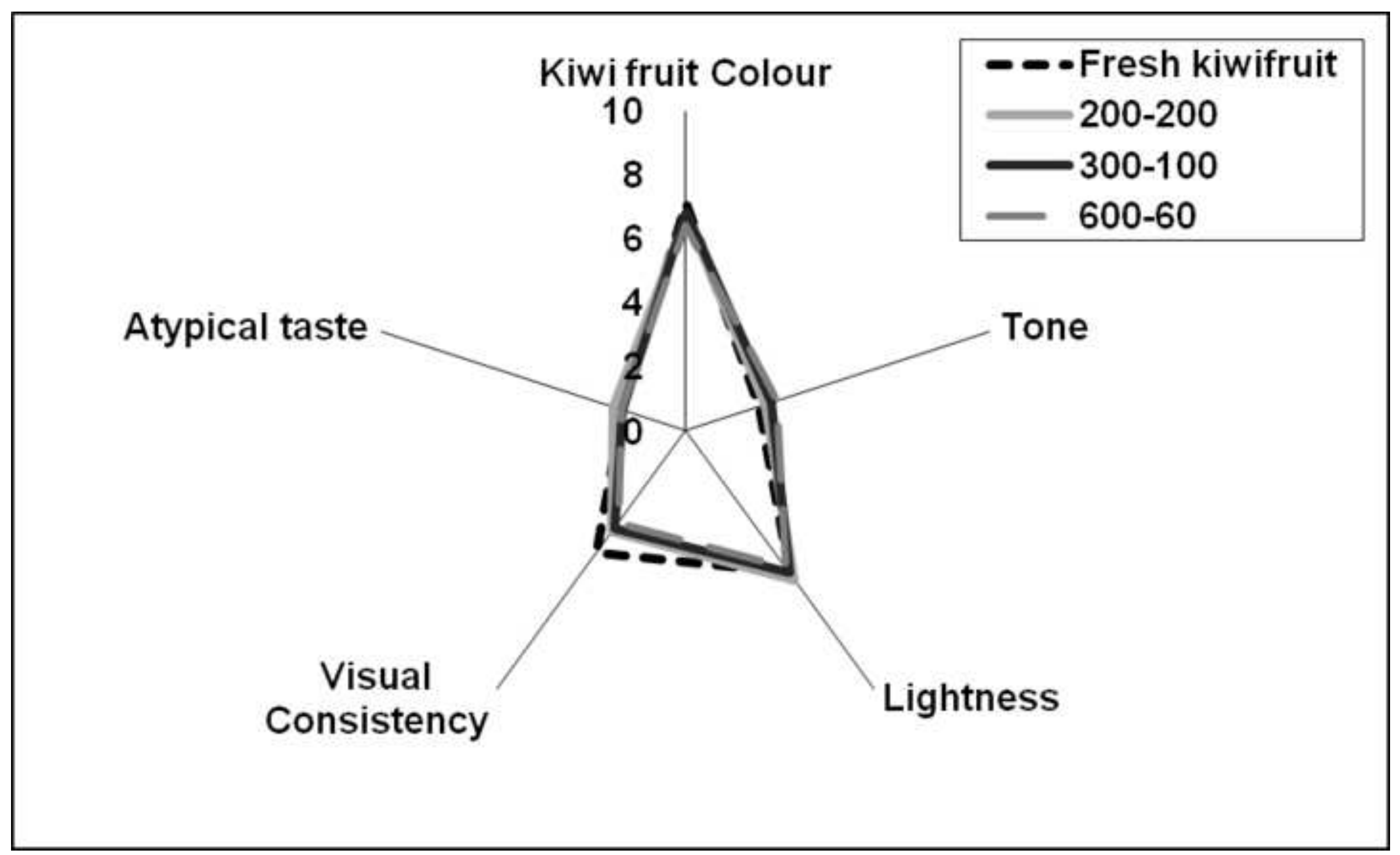




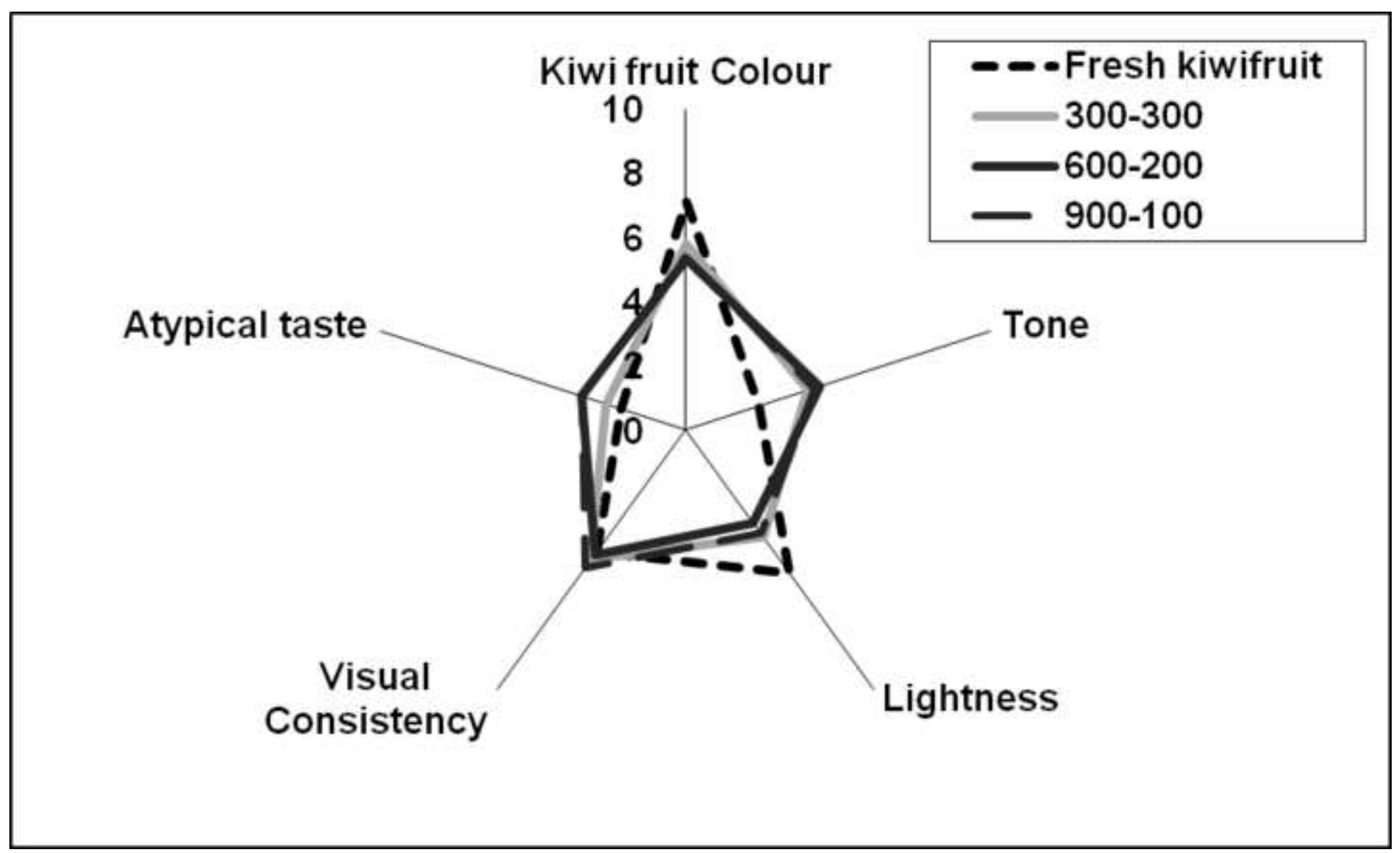




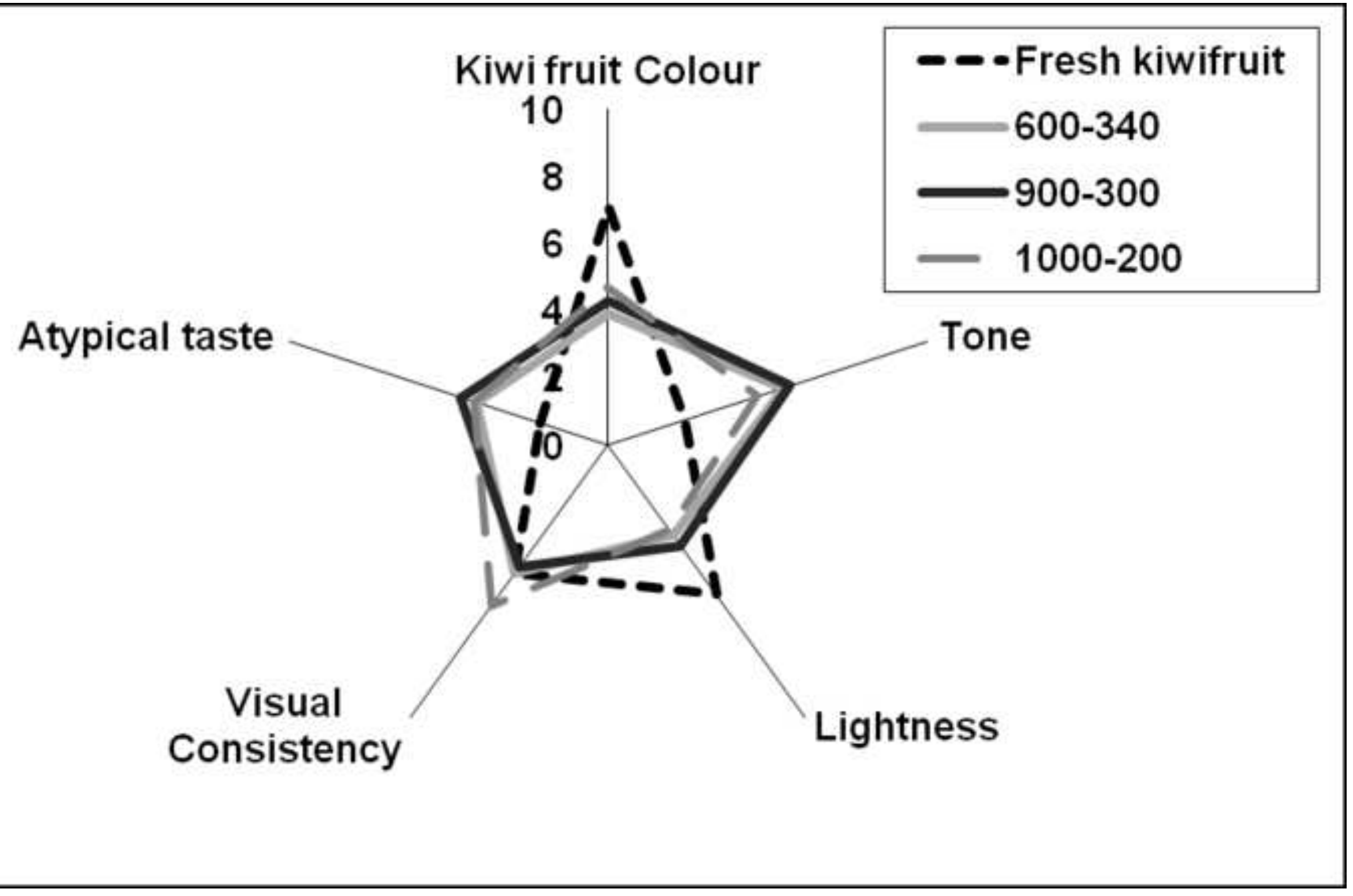


Click here to download high resolution image

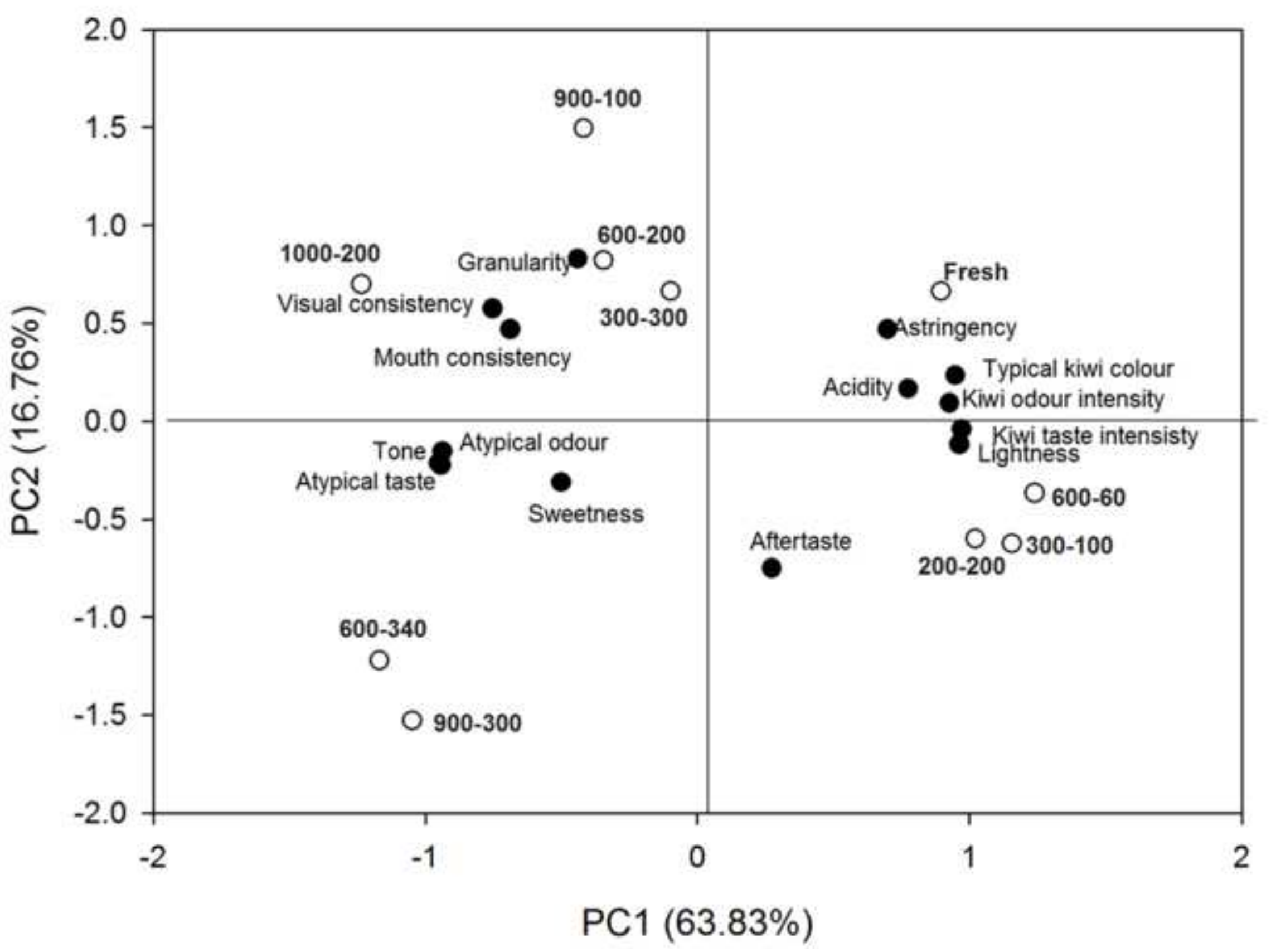


Table 1

Click here to download Table: Table 1.docx

\section{Table 1}

\begin{tabular}{|c|c|c|}
\hline Code & Power levels (W) & Time $(\mathbf{s})$ \\
\hline $200-200$ & 200 & 200 \\
\hline $300-100$ & 300 & 100 \\
\hline $300-300$ & 300 & 300 \\
\hline $600-60$ & 600 & 60 \\
\hline $600-200$ & 600 & 200 \\
\hline $600-340$ & 600 & 340 \\
\hline $900-100$ & 900 & 100 \\
\hline $900-300$ & 900 & 300 \\
\hline $1000-200$ & 1000 & 200 \\
\hline
\end{tabular}




\section{Table 2}

\begin{tabular}{|l|l|}
\hline Attribute and scale extremes & Technique \\
\hline Kiwi odour intensity (low/high) & Observe \\
\hline Atypical odour (low/high) & Observe \\
\hline Typical kiwi colour (low/high) & Observe \\
\hline Tone (green/brown) & Observe \\
\hline Lightness (light/dark) & Observe \\
\hline Granularity (low/high) & $\begin{array}{l}\text { Evenness of the sample's surface. Take a spoonful of the sample } \\
\text { and observe its surface. }\end{array}$ \\
\hline Visual consistency (low/high) & $\begin{array}{l}\text { Take enough quantity of kiwi puree with a spoon and drop it to } \\
\text { evaluate its visual consistency }\end{array}$ \\
\hline Sweetness (low/high) & $\begin{array}{l}\text { Taste the necessary quantity of kiwi puree to notice the intensity } \\
\text { of sweetness }\end{array}$ \\
\hline Acidity (low/high) & $\begin{array}{l}\text { Taste the necessary quantity of kiwi puree to notice the intensity } \\
\text { of acidity }\end{array}$ \\
\hline Astringency (low/high) & $\begin{array}{l}\text { Taste the necessary quantity of kiwi puree to notice the intensity } \\
\text { of astringency }\end{array}$ \\
\hline Intensity kiwi taste (low/high) & $\begin{array}{l}\text { Taste the necessary quantity of kiwi puree to notice the intensity } \\
\text { of typical kiwi taste }\end{array}$ \\
\hline Atypical taste (low/high) & $\begin{array}{l}\text { Taste the necessary quantity of kiwi puree to notice the intensity } \\
\text { of typical kiwi taste }\end{array}$ \\
\hline Aftertaste (low/high) & Assess the persistence of taste after ingesting kiwi puree \\
\hline Mouth consistency (low/high) & Taste the sample and evaluate its consistency during the ingest \\
\hline
\end{tabular}




\section{Table 3}

\begin{tabular}{|c|c|c|c|c|c|c|c|c|}
\hline Code & $\mathbf{L}^{*}$ & $\mathbf{a}^{*}$ & $\mathbf{b}^{*}$ & $\mathrm{C}^{*}$ & h* & $\Delta \mathbf{E}^{*}$ & BI & WI \\
\hline Raw kiwi fruit & $37.7(1.1) \mathrm{a}$ & $-2.2(0.6) \mathrm{a}$ & 23 (2)bcd & $24.3(0.5) \mathrm{bcd}$ & $95(2) \mathrm{bcd}$ & - & $47(2) c$ & $33.5(1.0) \mathrm{a}$ \\
\hline $200-200$ & $38.4(1.0) \mathrm{a}$ & $-2.1(0.3) \mathrm{ab}$ & $22(2) \mathrm{a}$ & $22(2) \mathrm{a}$ & $95.4(0.7) \mathrm{d}$ & $2.3(1.5) \mathrm{a}$ & $44(4) \mathrm{a}$ & $34.3(1.4) \mathrm{ab}$ \\
\hline $300-100$ & $39(2) a b$ & $-2.03(0.13) a b c$ & 23 (2)abc & 23 (2)abc & $95.2(0.5) \mathrm{cd}$ & $3.0(0.9) \mathrm{abc}$ & $44(2) a b$ & $35.0(1.3) \mathrm{bc}$ \\
\hline $300-300$ & $39.0(1.8) \mathrm{a}$ & $-1.7(0.5)$ cde & 24.4 (1.1)bcd & $24.1(0.9) \mathrm{bcd}$ & $93.9(1.3) \mathrm{a}$ & $1.6(1.0) \mathrm{a}$ & $47.4(1.1) \mathrm{c}$ & $34.0(1.1) \mathrm{ab}$ \\
\hline $600-60$ & $39(2) \mathrm{a}$ & $-2.0(0.2) \mathrm{abcd}$ & $21(2) \mathrm{a}$ & $22(2) \mathrm{a}$ & $95.3(0.6) \mathrm{cd}$ & $2.3(1.8) \mathrm{a}$ & $43(4) \mathrm{a}$ & $34.3(1.1) \mathrm{ab}$ \\
\hline $600-200$ & $42.3(1.1) \mathrm{cd}$ & -1.7 (0.4)abcde & $24.5(1.0) \mathrm{cd}$ & $24.4(1.1) \mathrm{cd}$ & $94.0(0.9) \mathrm{ab}$ & $4.4(1.1) \mathrm{cd}$ & $45.2(1.1) a b c$ & $37.3(0.8) \mathrm{d}$ \\
\hline $600-340$ & $42.0(1.6) \mathrm{cd}$ & $-1.7(0.2)$ bcde & $24.0(0.9) \mathrm{bcd}$ & $24.2(0.9) \mathrm{bcd}$ & $93.9(0.2) \mathrm{a}$ & 4.3 (1.4)bcd & $45.0(0.9) a b c$ & $37.3(1.2) \mathrm{d}$ \\
\hline $900-100$ & $40.5(1.0) b c$ & $-1.8(0.3)$ abcde & $24.3(0.9) \mathrm{d}$ & $24.5(0.9) \mathrm{d}$ & $94.2(0.8) a b c$ & $2.8(1.1) \mathrm{ab}$ & $46.3(1.1) b c$ & $35.8(0.8) \mathrm{c}$ \\
\hline $900-300$ & $42.4(1.1) \mathrm{d}$ & $-1.3(0.2) \mathrm{e}$ & $22.7(1.3) \mathrm{ab}$ & $22.7(1.1) \mathrm{ab}$ & $93.4(0.5) \mathrm{a}$ & $5.0(0.8) \mathrm{d}$ & $42.7(1.7) \mathrm{a}$ & $38.3(0.8) \mathrm{d}$ \\
\hline $1000-200$ & $43.3(1.8) \mathrm{d}$ & $-1.5(0.3) \mathrm{de}$ & 24.0 (1.3)bcd & 24.0 (1.4)bcd & $93.8(0.8) \mathrm{a}$ & $6(2) d$ & 44.0 (1.0)ab & $38.4(1.3) \mathrm{d}$ \\
\hline
\end{tabular}




\section{Table 4}

\begin{tabular}{|c|c|c|c|c|c|c|c|c|c|c|c|c|c|}
\hline VARIABLES & \multicolumn{13}{|c|}{ INSTRUMENTALS } \\
\hline SENSORIALS & Moisture & aw & ${ }^{\circ}$ Brix & $p H$ & Flow distance & Viscosity & $L^{*}$ & $a^{*}$ & $b^{*}$ & $C^{*}$ & $h^{*}$ & $B I$ & $W I$ \\
\hline Kiwi odour intensity & 0.704 & 0.040 & 0.294 & -0.091 & 0.916 & -0.720 & -0.764 & -0.823 & -0.444 & -0.427 & 0.846 & 0.140 & -0.471 \\
\hline Atypical odour & -0.754 & -0.131 & -0.190 & 0.091 & -0.854 & 0.834 & 0.841 & 0.841 & 0.307 & 0.288 & -0.830 & -0.238 & 0.735 \\
\hline Typical kiwi colour & 0.815 & -0.007 & 0.199 & -0.062 & 0.896 & -0.850 & -0.886 & \begin{tabular}{|l|}
-0.894 \\
\end{tabular} & -0.316 & -0.296 & 0.878 & 0.310 & -0.700 \\
\hline Tone & -0.801 & 0.021 & -0.251 & 0.138 & -0.877 & 0.828 & 0.868 & 0.936 & 0.331 & 0.310 & -0.923 & -0.289 & 0.649 \\
\hline Lightness & 0.612 & -0.259 & 0.521 & -0.152 & 0.946 & -0.752 & -0.885 & \begin{tabular}{|l|}
-0.881 \\
\end{tabular} & -0.579 & -0.561 & 0.932 & 0.135 & -0.532 \\
\hline Granularity & 0.247 & 0.467 & -0.910 & 0.384 & -0.443 & 0.104 & 0.417 & 0.261 & 0.763 & 0.762 & -0.436 & 0.214 & -0.079 \\
\hline Visual consistency & -0.167 & 0.317 & -0.757 & 0.475 & -0.715 & 0.520 & 0.589 & 0.561 & 0.787 & 0.779 & -0.704 & 0.257 & 0.189 \\
\hline Acidity & 0.704 & -0.171 & 0.230 & -0.410 & 0.767 & -0.619 & -0.584 & -0.701 & -0.311 & -0.297 & 0.705 & 0.157 & -0.279 \\
\hline Sweetness & -0.601 & 0.369 & 0.064 & 0.146 & -0.541 & 0.642 & 0.709 & 0.480 & 0.060 & 0.048 & -0.441 & -0.645 & 0.405 \\
\hline Astringency & 0.683 & 0.179 & 0.026 & -0.403 & 0.535 & -0.891 & -0.606 & \begin{tabular}{|l|}
-0.668 \\
\end{tabular} & -0.256 & -0.243 & 0.673 & 0.096 & -0.525 \\
\hline Intensity kiwi taste & 0.690 & -0.099 & 0.380 & -0.185 & 0.923 & -0.816 & -0.888 & \begin{tabular}{|l|}
-0.900 \\
\end{tabular} & -0.454 & -0.434 & 0.919 & 0.203 & -0.636 \\
\hline Atypical taste & -0.791 & -0.018 & -0.215 & 0.213 & -0.868 & 0.866 & 0.932 & 0.877 & 0.296 & 0.276 & -0.864 & -0.410 & 0.701 \\
\hline Aftertaste & -0.210 & -0.429 & 0.639 & 0.314 & 0.446 & 0.124 & -0.216 & -0.197 & -0.589 & -0.587 & 0.309 & -0.269 & 0.130 \\
\hline Mouth consistency & -0.077 & 0.134 & -0.766 & 0.649 & -0.584 & 0.548 & 0.513 & 0.509 & 0.856 & 0.851 & -0.688 & 0.360 & 0.057 \\
\hline
\end{tabular}

